\title{
Suicidal Presentations to Emergency Departments in a Large Australian Public Health Service over 10 Years
}

\author{
Nicolas J.C. Stapelberg ${ }^{1,2, *}$, Jerneja Sveticic ${ }^{1}\left(\mathbb{D}\right.$, Ian Hughes ${ }^{1}$ and Kathryn Turner ${ }^{1}(\mathbb{C}$ \\ 1 Mental Health and Specialist Services, Gold Coast Hospital and Health Services, Southport, QLD 4215, \\ Australia; jerneja.sveticic@health.qld.gov.au (J.S.); Ian.Hughes2@health.qld.gov.au (I.H.); \\ kathryn.turner@health.qld.gov.au (K.T.) \\ 2 Faculty of Health Sciences \& Medicine, Bond University, Robina, QLD 4226, Australia \\ * Correspondence: Chris.Stapelberg@health.qld.gov.au
}

Received: 17 July 2020; Accepted: 13 August 2020; Published: 14 August 2020

\begin{abstract}
This paper presents trends and characteristics for 32,094 suicidal presentations to two Emergency Departments (EDs) in a large health service in Australia across a 10-year period (2009-2018). Prevalence of annual suicidal presentations and for selected groups of consumers (by sex, age groups, and ethnicity) was determined from a machine learning diagnostic algorithm developed for this purpose and a Bayesian estimation approach. A linear increase in the number of suicidal presentations over 10 years was observed, which was 2.8-times higher than the increase noted in all ED presentations and 6.1-times higher than the increase in the population size. Females had higher presentation rates than males, particularly among younger age groups. The highest rates of presentations were by persons aged 15-24. Overseas-born persons had around half the rates of suicidal presentations than Australian-born persons, and Indigenous persons had 2.9-times higher rates than non-Indigenous persons. Of all presenters, $70.6 \%$ presented once, but $5.7 \%$ had five or more presentations. Seasonal distribution of presentations showed a peak at the end of spring and a decline in winter months. These findings can inform the allocation of health resources and guide the development of suicide prevention strategies for people presenting to hospitals in suicidal crisis.
\end{abstract}

Keywords: suicide; self-harm; emergency department; machine learning; Bayesian method

\section{Introduction}

Suicide is a global, complex phenomenon that results in an annual loss of more than 800,000 lives worldwide [1]. In Australia, 3046 people died by suicide in 2018, accounting for a standardized suicide rate of 12.1 per 100,000 [2]. Intentional self-harm was ranked as the 13th leading cause of death across all ages and represented $1.9 \%$ of total mortality in Australia. Approximately one third of deaths among people aged under 35 years was attributed to suicide [2].

The World Health Organization [1] has recommended regular monitoring of suicide rates as the backbone to effective national suicide prevention strategies. While many countries have national systems that record, collect and process information related to suicide (albeit with varying degrees of accuracy due to the challenges related to misclassifications of true causes of death [1]), very few have equivalent systems specifically dedicated to non-fatal suicidal behaviors [3]. The true prevalence of a range of suicidal behaviors in the general population therefore remains difficult to gauge and is further obfuscated by the fact that most people never seek help for suicide-related concerns [4]. A large community survey conducted in Australia reported a ratio of completed:attempted suicide to be 1 to $23[5]$.

One of the most frequently utilized methods of estimating the incidence of non-fatal suicidal behavior is by noting such behavior on presentation to health facilities, most typically Emergency 
Departments (EDs), even if these account for only a subset of the actual community incidence [6-8]. Trends of presentations with non-fatal suicidal behavior to one Australian hospital (which represents a part of the health service investigated in the present paper) were recently analyzed by Kõlves et al. [9]. The authors found a significant increase in the age-standardized rates of non-fatal suicidal presentations for both males and females, and particularly among the youth. Further, $13.4 \%$ of the sample re-presented with within one year after their index episode [9]. Studies with longer follow-up periods reported higher rates of repeated non-fatal suicidal behaviors, such as $21.6 \%$ in a study of patients followed for 10 years [10]. Presentations with suicidal ideation have a higher rate of re-presentations than suicide attempts [11] and are more frequent among males than females [11,12]. Racial and ethnic differences have also been found to impact on rates of suicidal presentations to EDs, with evidence of members of ethnic minority groups displaying a higher risk of suicide yet being less likely to engage with mental health services $[13,14]$.

Recent studies analyzed trends in hospital presentations combining suicidal ideation and attempts by identifying study populations through relevant diagnostic codes or presenting complaints assigned to ED encounters [15-17]. However, there is evidence that ED administrative data under-estimate the true volume of suicidal presentations by around $60 \%$ due to heterogeneity of their coding $[18,19]$, prompting calls to develop more sensitive processes to improve their identification [20].

In 2016, the Gold Coast Hospital and Health Service (GCHHS) initiated a Suicide Prevention Strategy [21] based on the Zero Suicide Framework (ZSF) [22]. ZSF is a systems approach to suicide prevention underpinned by data-driven evaluation and continuous quality improvement, which is reliant on accurate and timely data acquisition. To overcome the above noted limitations inherent to the use of ED administrative data and to reduce high costs associated with manual identification of relevant cases, a machine learning algorithm was developed to identify suicidal presentations using presentation descriptions in the Emergency Department Information System (EDIS) database [23]. This algorithm was used to obtain data on suicidal presentations between 2009 and 2018 which were analyzed in this paper. The paper has four main aims:

- To analyze trends in suicidal presentations over a 10-year period;

- To analyze sociodemographic information of consumers with suicidal presentations (age, sex, ethnicity);

- To analyze the frequency of suicidal re-presentations; and

- To identify seasonal patterns of suicidal presentations.

\section{Materials and Methods}

\subsection{Context}

This work was conducted within the GCHHS which provides public mental health services for a population of around 600,000 people [24]. GCHHS has two EDs (Gold Coast University Hospital and Robina Hospital) that represent the largest primary points of presentation for persons of all ages at risk of suicide. A cohort of all suicidal presentations to EDs between 1 January 2009 and 31 December 2018 was examined $(N=1,402,518)$.

\subsection{Identification of Suicidal Presentations}

The initial identification of suicidal cases was performed using a machine learning algorithm, the "Searching EDIS for Records of Suicidal Presentations" (SERoSP) [23]. SERoSP uses an evolutionary algorithm to weight 136 variables from a training dataset of EDIS data (March-May 2015), where suicidal presentations were identified by a psychiatrist. These variables included a range of diagnostic codes and presenting problems assigned at the point of ED triage such as Indigenous/non-Indigenous status of the consumer, score according to the Australian Triage Scale (5-point clinical tool used to establish the maximum waiting time for medical assessment and treatment of a patient), discharge destinations, and 52 different keywords indicative of the presentations being suicide-related. The program then 
"learned" from trial and error, over 150 successive generations, using 100 variations of variable weights per generation, to detect suicidal presentations with a sensitivity of $95 \%$ and a specificity of $92 \%$. This algorithm was designated as SERoSP1. Further work was then undertaken to increase the sensitivity and specificity of the algorithm by emphasizing analysis of triage text using word and phrase search strategies, and employing basic Natural Language Processing techniques to identify key words and word combinations used in the triage text of suicidal presentations. The modified algorithm was retrained on 23,786 psychiatrist-assessed ED presentations (July-December 2015) and validated on 26,130 psychiatrist-assessed ED presentations (July-December 2017), achieving a sensitivity of $87 \%$ for a pre-set specificity of $99 \%$. This algorithm is referred to as SERoSP2.

Following a well-used concept in clinical medicine where a highly sensitive test is run as a screening test followed by a high-specificity test to then confirm or reject a diagnosis $[25,26]$, SERoSP1 was run first to 'screen' cases, theoretically missing only few cases, but incorporating a substantial number of false positives, followed by the SERoSP2 which eliminated as many false positives as possible. The combination was tested against the 26,130 human-assessed ED validation dataset (July-December 2017) which the SERoSP1-SERoSP2 combination had not been exposed to before. This resulted in a specificity of 0.972 ( $95 \%$ confidence intervals (CI): 0.969-0.974) when the sensitivity was set at 0.968 (0.960-0.974).

SERoSP algorithm was unable to discriminate between suicide attempts, non-suicidal self-injury, and suicidal ideation based on EDIS data. This is in part because EDIS data is entered before a detailed mental health assessment occurs and the information contained therein is less detailed than those recorded into consumers' clinical notes upon a more thorough assessment by a mental health practitioner. Therefore, throughout the paper, the term "suicidal presentations" is used to describe all suicide and self-harm related incidents.

\subsection{Statistical Analysis}

Diagnostic tests are commonly used for prevalence surveys, however, unless the test is perfect (i.e., with sensitivity and specificity of 1), the observed prevalence must be adjusted to estimate the true prevalence $[27,28]$. Both traditional (frequentist) and Bayesian methods have been developed to estimate true prevalence. When the expected prevalence is low, assumptions required for frequentist approaches may not be met and unrealistic point estimates and wide confidence intervals result [27,29]. In this work, we use a Bayesian approach described by Joseph et al. [30] and utilized through Epitools (Bayesian estimation of true prevalence from survey testing with one test) [31]. The accuracy of Bayesian estimates is dependent on the quality of prior knowledge regarding sensitivity and specificity of the test and expectation of the prevalence [29]. Prior estimates of the sensitivity and specificity, in all cases, were those obtained from the SERoSP1-SERoSP2 diagnostic combination on the validation dataset. The prior estimate of the prevalence, in each case, was based on a crude adjustment of the observed prevalence based on the proportion of false positives seen in the validation dataset. Probability distributions of these prior estimates were based on the beta distribution with parameters, $\alpha$ and $\beta$, calculated from the point estimate and its $5 \% \mathrm{CI}$ for sensitivity and specificity or, for prevalence, from the adjusted number of positives, $x$, and the population total, $n(\alpha=x+1, \beta=n-x+1)[30,31]$.

The posterior estimates of prevalence obtained are medians with $95 \%$ equally tailed credible intervals. The $95 \%$ credible interval (CDI) is the Bayesian equivalent to a $95 \% \mathrm{CI}$ and is the interval in which the parameter (median in this instance) falls with $95 \%$ probability. The posterior probability densities, and hence CDIs, may be highly skewed [30]; hence, when the prevalence estimates are used to estimate the number of presentations, the sum of estimated presentations from subgroups may not necessarily equal the estimate calculated for the total. In this paper, medians and $95 \%$ CDIs are presented for annual estimates but only medians are shown for smaller subgroups.

Annual sex-based and age-specific rates were calculated using the Gold Coast estimated resident population figures for the years 2009-2018 [24]. For Indigenous population and country of birth figures, census data from 2011 and 2016 were used [24]. Comparisons between rates were performed using 
incident rate ratios (IRRs). Trend lines were examined using linear regression models, and annual percentage changes (APC) with $95 \% \mathrm{CI}$ are presented. Presentation-based data is used in all analyses apart from the frequency of re-presentations, where person-based data is employed. The likelihood of re-presentations is compared between groups using odds ratios (OR). All analyses were performed using SPSS, Version 24 (IBM Corp., Armonk, NY, USA) [32].

\subsection{Research Ethics}

This work was performed as part of the project Gold Coast Mental Health and Specialist Services Suicide Prevention Strategy: Evaluation. It was recognized as Quality Activity by the GCHSS Human Research Ethics Committee and granted a research ethics exemption (LNR/2018/ QGC/47473).

\section{Results}

\subsection{Rates of Suicidal Presentations}

Between 2009 and 2018, 32,094 suicidal presentations to Gold Coast Emergency Departments were identified. Table 1 shows the numbers of annual suicidal presentations, alongside the $95 \%$ CDIs for the prevalence using the Bayesian estimates. On average, suicidal presentations accounted for $2.2 \%$ of all ED presentations, with a substantial increase in this proportion from 1.3\% in 2009 to $3.1 \%$ in 2018 .

Table 1. Suicidal presentations to Gold Coast Emergency Departments, 2009-2018.

\begin{tabular}{|c|c|c|c|c|c|c|c|}
\hline \multirow{2}{*}{ Year } & \multirow{2}{*}{$\begin{array}{c}\text { Suicidal } \\
\text { Presentations } \\
N(95 \% \text { CDI })\end{array}$} & \multirow{2}{*}{$\begin{array}{c}\text { All ED } \\
\text { Presentations }\end{array}$} & \multirow{2}{*}{$\begin{array}{c}\text { Suicidal } \\
\text { Presentations } \\
\text { as } \% \text { of All ED }\end{array}$} & \multirow{2}{*}{$\begin{array}{c}\text { Gold } \\
\text { Coast } \\
\text { Population }\end{array}$} & \multicolumn{3}{|c|}{$\begin{array}{l}\text { Rates of Suicidal Presentations } \\
\text { (Per 100,000 Population) }\end{array}$} \\
\hline & & & & & Males & Females & Persons \\
\hline 2009 & $\begin{array}{c}1446 \\
(1334-1557)\end{array}$ & 111,201 & 1.3 & 495,835 & 258.0 & 299.8 & 291.6 \\
\hline 2010 & $\begin{array}{c}1652 \\
(1542-1762)\end{array}$ & 110,114 & 1.5 & 506,135 & 294.0 & 334.6 & 326.3 \\
\hline 2011 & $\begin{array}{c}2089 \\
(2090-2205)\end{array}$ & 116,055 & 1.8 & 515,202 & 374.9 & 411.3 & 405.5 \\
\hline 2012 & $\begin{array}{c}2467 \\
(2468-2590)\end{array}$ & 123,346 & 2.0 & 528,342 & 406.9 & 501.0 & 466.9 \\
\hline 2013 & $\begin{array}{c}2798 \\
(2664-2931)\end{array}$ & 133,231 & 2.1 & 540,687 & 450.6 & 533.7 & 517.5 \\
\hline 2014 & $\begin{array}{c}3376 \\
(3230-3523)\end{array}$ & 146,800 & 2.3 & 550,718 & 568.1 & 630.5 & 613.1 \\
\hline 2015 & $\begin{array}{c}3756 \\
(3599-3912)\end{array}$ & 156,487 & 2.4 & 561,629 & 597.6 & 709.6 & 668.7 \\
\hline 2016 & $\begin{array}{c}4246 \\
(4083-4410)\end{array}$ & 163,319 & 2.6 & 575,303 & 698.0 & 720.7 & 738.1 \\
\hline 2017 & $\begin{array}{c}4884 \\
(4716-5052)\end{array}$ & 168,416 & 2.9 & 591,356 & 785.7 & 809.0 & 825.9 \\
\hline 2018 & $\begin{array}{c}5380 \\
(5207-5554)\end{array}$ & 173,549 & 3.1 & 606,774 & 873.4 & 871.4 & 886.7 \\
\hline 2009-2018 & $\begin{array}{c}32,094 \\
(30,855-35,063)\end{array}$ & $1,402,521$ & 2.2 & $5,471,981$ & 542.5 & 594.8 & 586.5 \\
\hline
\end{tabular}

Notes: CDI - Credible Interval. ED - Emergency Department.

The annual percentage change in the number of suicidal presentations was 13.5\% (95\%CI 11.2-15.8). This increase was 2.8-times higher than the increase noted in all ED presentations (APC $=4.8 \%, 95 \% \mathrm{CI}$ 2.9-6.6), and 6.1-times higher than the increase in the population size (APC $=2.2 \%, 95 \% \mathrm{CI} 2.0-2.4$ ) during the same time.

Combining presentations across the 10-year period, females had higher rates of suicidal presentations than males (594.8 vs. 542.5 per 100,000; IRR $=1.10,95 \%$ CI 1.07-1.12). However, the increase in rates during the observed decade was larger for males (3.4-fold) than females (2.9-fold increase). For all persons, rates of suicidal presentations increased 3.0-fold between 2009 and 2018. 


\subsection{Demographic Characteristics}

Figure 1 shows that the highest rates of presentations were by persons aged 15-24, which accounted for $37.4 \%$ of presentations by females and $28.1 \%$ of presentations by males. This was followed by those aged $25-34$ (accounting for $25.2 \%$ of females' presentations and $18.7 \%$ of males') and $35-44$ (22.3\% of males' and $17.7 \%$ of females' presentations). Low rates of presentations are seen by older persons, with only $2.6 \%$ of all presentations by males and $3.2 \%$ of presentations by females in the $65+$ age group.

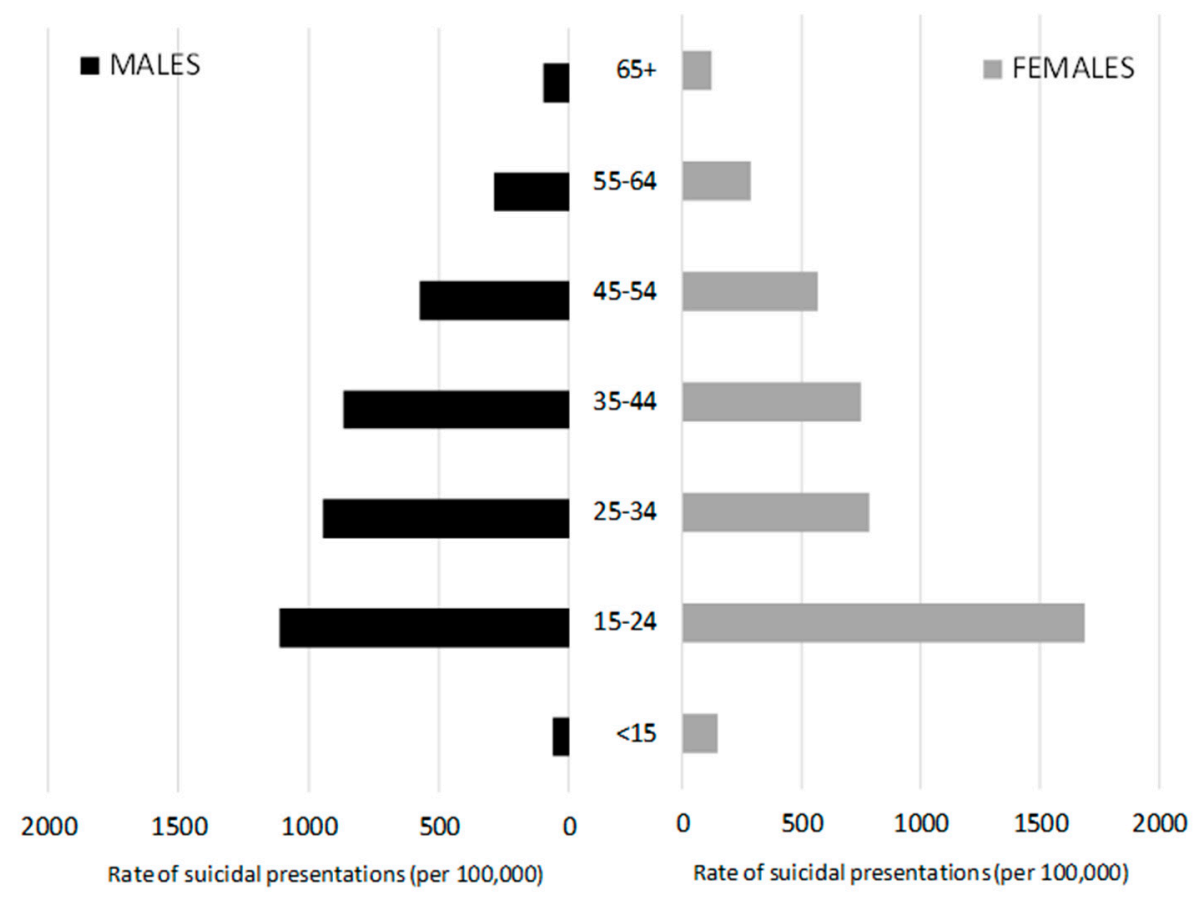

Figure 1. Age-specific rates of suicidal presentations by males and females, 2009-2018.

Across the 10-year period, 6646 suicidal presentations (20.7\%) were by overseas-born persons, and $1363(4.2 \%)$ were by persons identified as being of Indigenous background. Figure 2 compares rates of suicidal presentations for different ethnicity groups. Overseas-born persons had around half the rate of suicidal presentations as Australian-born persons (IRR $=0.44,95 \% \mathrm{CI} 0.42-0.45$ ), with this ratio the same in males and females. Persons of Indigenous background had 2.8-times (95\%CI 2.62-2.93) higher rates of suicidal presentations than non-Indigenous persons, with this difference more pronounced among males (IRR $=2.96,95 \% \mathrm{CI} 2.73-3.20)$ than females (IRR $=2.64,95 \% \mathrm{CI} 2.45-2.86$ ).

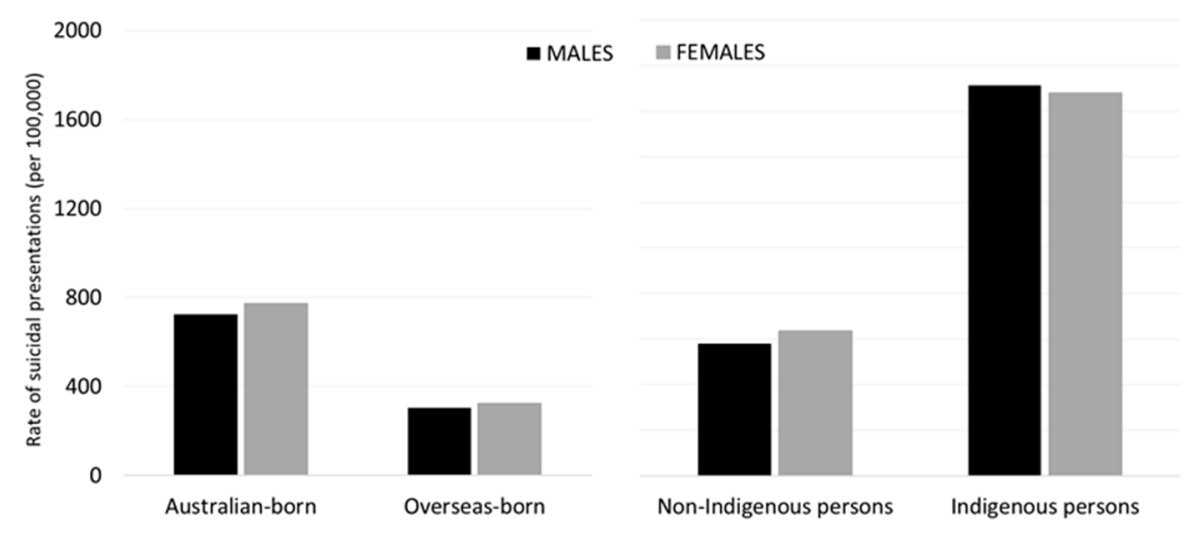

Figure 2. Rates of suicidal presentations by ethnicity groups, 2009-2018. 


\subsection{Repeated Suicidal Presentations}

As seen in Table 2, the total of 32,094 presentations over the 10-year period were attributed to 20,526 persons. The majority of persons $(70.6 \%$ ) presented once, $23.7 \%$ had $2-4$ presentations, and $5.7 \%$ were considered to be "frequent presenters" [33] by having a total of five or more presentations during the observed 10-year period.

Table 2. Frequency of suicidal presentations per person, 2009-2018.

\begin{tabular}{|c|c|c|c|c|}
\hline & $N^{1}$ (Persons) & $\begin{array}{c}1 \\
\text { Presentation } \\
N(\%)\end{array}$ & $\begin{array}{c}2-4 \\
\text { Presentations } \\
N(\%)\end{array}$ & $\begin{array}{c}5 \text { or More } \\
\text { Presentations } \\
N(\%)\end{array}$ \\
\hline All persons & 21,220 & $14,974(70.6 \%)$ & $5028(23.7 \%)$ & $1218(5.7 \%)$ \\
\hline \multicolumn{5}{|c|}{ Sex } \\
\hline Males & 10,341 & $7360(71.2 \%)$ & $2402(23.2 \%)$ & $579(5.6 \%)$ \\
\hline Females & 11,249 & $7928(70.5 \%)$ & $2676(23.8 \%)$ & $644(5.7 \%)$ \\
\hline \multicolumn{5}{|c|}{ Age groups ${ }^{2}$} \\
\hline Under 15 & 886 & $558(62.9 \%)$ & $231(26.0 \%)$ & $98(11.0 \%)$ \\
\hline 15-24 & 6752 & $4542(67.3 \%)$ & $1692(25.1 \%)$ & $519(7.7 \%)$ \\
\hline $25-34$ & 4738 & 3396 (71.7\%) & $1070(22.6 \%)$ & $273(5.8 \%)$ \\
\hline $35-44$ & 4000 & $2831(70.8 \%)$ & $978(24.4 \%)$ & $192(4.8 \%)$ \\
\hline $45-54$ & 2817 & $2030(72.0 \%)$ & $623(22.1 \%)$ & $165(5.8 \%)$ \\
\hline $55-64$ & 1291 & $967(74.9 \%)$ & $275(21.3 \%)$ & $49(3.8 \%)$ \\
\hline $65+$ & 953 & $831(87.2 \%)$ & $112(11.8 \%)$ & $10(1.1 \%)$ \\
\hline \multicolumn{5}{|c|}{ Country of birth } \\
\hline Australian-born & 16,752 & $11,599(69.2 \%)$ & $4126(24.6 \%)$ & $1027(6.1 \%)$ \\
\hline Overseas-born & 4789 & $3651(76.2 \%)$ & $943(19.7 \%)$ & $194(4.1 \%)$ \\
\hline \multicolumn{5}{|c|}{ Indigenous status } \\
\hline Indigenous & 746 & $450(60.4 \%)$ & $223(29.8 \%)$ & $73(9.8 \%)$ \\
\hline Non-Indigenous & 20,568 & $14,605(71.0 \%)$ & $4817(23.4 \%)$ & $1146(5.6 \%)$ \\
\hline
\end{tabular}

Notes: ${ }^{1}-\mathrm{N}$ refers to the sum of estimates of presentations for subgroups rather than the estimate for the whole group (see Methods for more details). This allowed for meaningful \% values to be shown. ${ }^{2}-$ When a person had more than one suicidal presentation, the age at their first presentation was included in the analysis.

The frequency of repeated presentations differed between persons depending on their age of first presentation, country of birth, and Indigenous status, but not sex. A greater likelihood to have more than one suicidal presentation was noted in persons aged less than 15 years (OR $=1.44,95 \% \mathrm{CI}$ $1.26-1.66)$ and those aged $15-24$ years ( $\mathrm{OR}=1.27$, 95\% CI 1.19-1.35), when compared to other age groups. In contrast, persons whose first presentation was when aged 65 or more were more likely to only have only one presentation during the observed 10 years $(\mathrm{OR}=2.93,95 \% \mathrm{CI} 2.42-3.55)$. Australian-born persons were 1.42-times more likely to have multiple presentations than overseas-born persons $(95 \% \mathrm{CI}$ 1.32-1.53), and Indigenous persons were 1.61-times (95\%CI 1.38-1.87) more likely to have multiple presentations than non-Indigenous persons. The two groups of persons with the highest likelihood of being frequent presenters were youth under 15 years (11.1\%) and Indigenous Australians (9.8\%).

\subsection{Seasonality of Suicidal Presentations}

Figure 3 shows the distribution of suicidal presentations across months, combining data for all 10 years. The highest percentage of presentations occurred between October and December, with a distinct peak in November $(10.5 \%, 95 \%$ CI 10.1-10.9), which marks the end of spring in the southern hemisphere. This was followed by another, though smaller increase in March (start of autumn) with 9.0\% (95\%CI 8.6-9.4) of all suicidal presentations. The lowest percentage of suicidal presentations occurred in winter months (June and July) which accounted for $7.2 \%(95 \% \mathrm{CI} 6.9-7.6)$ and $7.4 \%(95 \% \mathrm{CI}$ 7.0-7.8) of suicidal presentations, respectively. No differences in the monthly distribution of suicidal presentations were observed between males and females $(\chi 2(11)=12.25, p=0.345)$. 


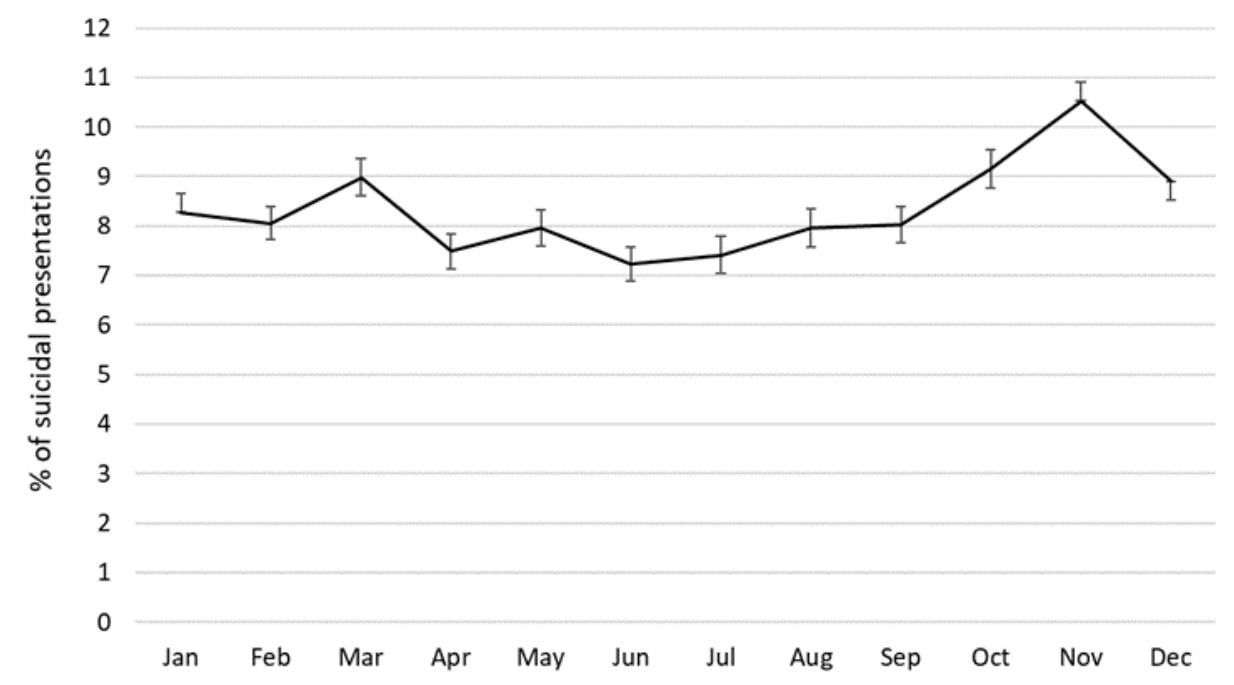

Figure 3. Seasonal distribution of suicidal presentations, 2009-2018.

\section{Discussion}

The use of a machine learning algorithm for the identification of suicidal presentations in ED administrative data introduces an innovative methodological approach to epidemiological suicidology. Results showed that rates of suicidal presentations to EDs in a large Australian public health service have tripled over a 10-year period; this increase was significantly greater than the overall increase in population size and in total ED presentations over the same period. This finding replicates similar results observed in New South Wales, Australia [17], and adds to the well-established literature on such increases when considering only suicide attempts [9,34].

Whilst it is possible that the observed trends reflect realistic increases in the number of persons experiencing suicidal crises in the geographical area included in the present analysis, reasons for it (such as potential sequalae of the 2007 economic recession as observed by Milner et al. [35]) could not be explored here. Other contributing factors need to be considered, such as attitudinal changes related to help-seeking behaviors, changes in referral pathways and models of care, or the (un)availability of alternative sources of support for acutely suicidal persons [36-38]. Finally, it is possible that the introduction of training programs, such as Suicide Risk Assessment and Management in Emergency Department Settings (SRAM-ED) program in 2015 [39], have improved the recording of relevant clinical details pertaining to suicidality in ED triage notes, increasing their probability of identification by the machine learning algorithm used in this work.

Demographic and socioeconomic variables associated with suicide risk have been the subject of many epidemiological studies, though typically limited to deaths by suicide or suicide attempts [40,41]. In this work, which combined presentations with suicidal ideation and suicide attempts, rates by females were found to be higher than by males. This is in contrast with findings by Perera, Wand, Bein, Chalkley, Ivers, Steinbeck, Shields, and Dinh [17] who noted a nearly equal division between males and females. A previously published analysis of a subset of presentations included in this paper [18] found that in 2017, 63.4\% of all suicidal presentations to ED were due to suicidal ideation. Considering the emerging evidence that males have higher rates of ED presentations with suicidal ideation [11], it could be expected that males would account for a larger proportion of suicidal presentations compared to females in our sample, however, the inability to differentiate between types of presentations prevented a more in-depth exploration of these trends.

Persons aged 15-24 accounted for the largest number and had the highest rate of suicidal presentation across the 10 years. Recent increases in suicide attempts by young people, and in particularly young men, have previously been observed [9]. Some authors have linked this to earlier age of onset of puberty and with it, earlier onset of depression and other mental health concerns, increased exposure to media portrayals of suicide, and increased use of social media which may 
facilitate the development of suicidal thoughts and attempts [42,43]. As noted above, a differential analysis of trends of suicide ideation and suicide attempts in different age groups is required to allow for identification of vulnerable groups that require most urgent responding.

Overseas-born persons' rate of suicidal presentation was about half of that observed for Australian-born people. This follows the previously observed disparity between suicide rates of first-generation migrants in Queensland, which are significantly lower than those of Australian-born persons [44]. Differences between the two groups was higher than reported in the analysis of deaths by suicide by Kolves and De Leo [44], which could be attributed to immigrants' reluctance to utilize mental-health services for suicide-related concerns [45]. Similarly, many Indigenous people experience significant barriers in accessing culturally appropriate support for mental health more broadly, and in particular for suicidality [46], which is believed to contribute to the 2.2-times higher suicide rate in Indigenous persons compared to non-Indigenous persons [47]. Despite the previously argued reluctance by many Indigenous Australians to engage with Western-based medical models of treatment [48], their rates of suicidal presentations to our EDs remained much higher than those of non-Indigenous persons. It is possible that among presentations by Indigenous persons included in our analysis, a greater proportion resulted from suicide attempts, particularly if using methods that are more likely to require medical interventions [14] or were involuntary in nature [49].

High repetition rates of suicidal presentations have previously been noted in Australian [9] and Irish [3] studies of hospital presentations with suicide attempts, although differences in follow-up times and the inclusion of suicidal ideation in our analyses prevent direct comparisons of findings. We contribute to the existing literature a delineation of the risk of re-presentation for different demographic and ethnic groups. Persons that were most likely to have repeated presentations belong to the same groups that had the highest rates of suicidal presentations: youth and Indigenous Australians. To a degree, this may be a consequence of different units of measurements (presentation-level when calculating rates, and person-level when analyzing re-presentations), and the fact that some older people presenting with suicidality may have died before the completion of the 10 year follow up period.

Analysis of monthly distribution of suicidal presentations to EDs identified a distinct peak at the end of spring (in November) and the lowest frequency during winter months. This finding partially aligns with previously observed seasonal patterns in deaths by suicide in Australia, which typically peak in spring/early summer and dip in autumn (for females) and winter (for males) [50,51]. However, some studies have found the distribution of non-fatal suicidal behaviors across the year to be less pronounced, arguably due to the predominant use of low-risk methods that have the least pronounced seasonal variations [41], such as cutting and poisoning, in suicide attempts. Potential variations in the prevalence of suicidal ideation, specifically within the subset of the population that access ED for help, currently remains a little researched topic outside of the debate on seasonal depression, which is believed to be less prominent in tropic areas of the southern hemisphere [52]. It is possible that other factors contributed to the observed trends in our study, such as the large numbers of domestic and international travelers visiting the Gold Coast at different times of the year, which has previously been found to have a significant impact on the volume of ED presentations [53]. The observed peak in suicidal presentations in November could therefore be partly due to the mass gathering of high school leavers ("schoolies") in the area, which has been linked to an increase in the number of mental health related presentations to ED during that time [54]. A more detailed investigation of seasonal trends of different types of suicidal presentations, further separated by sex and age groups, is required to disentangle the effects of these associations.

\section{Limitations}

There are limitations of this work that warrant consideration. Any diagnostic test used for surveillance purposes that is not perfect will provide prevalence estimates that come with error. The combined SERoSP1-SERoSP2 test had high levels of sensitivity and specificity, however, when applied to rare events, even tests as accurate as this produce large numbers of false positives and 
hence require an adjustment of the observed prevalence. The Bayesian method used in this work provided the best available estimates but is very dependent on high quality prior information. For the purposes of this analysis, it was assumed that the accuracy observed in the validation dataset (using 2017 data) provided a good estimate of the test's performance in populations from other years and in specific subgroups. Similarly, it was assumed that the proportion of false positives seen in the validation dataset would be similar in other population groups, enabling a reasonably good prior estimate of prevalence.

The size of the population for which the prevalence is being estimated also contributes to the accuracy of the estimate. This means it was not possible to accurately estimate the prevalence for some small populations (e.g., separate annual presentations by sex and age groups) nor could we obtain age-standardized rates that would allow for more meaningful comparisons between populations that are known to have different age-structured populations (most notably, Indigenous and non-Indigenous Australians). We acknowledge this as a limitation of this paper. It is also possible that the numbers of suicidal presentations by Indigenous people and first-generation migrants are under-estimated in our analysis, as has been noted in some earlier studies [55,56], particularly in the early years before GCHHS invested concentrated efforts towards improving the recording of sociodemographic characteristics of its consumers [57]. In analyzing re-presentations to ED, different periods of follow-up were applied to consumers depending on the year of their index presentation. Finally, we could not control for the possibility that some persons died during the follow-up period (particularly those of older age at the time of their index presentation) or have had repeated suicidal presentations to health services outside of the Gold Coast geographical catchment boundaries.

The inability of the developed algorithm to differentiate between types of suicidal presentations presents a limitation of the current work. We note that while the method presented here is suitable for surveillance and as a means to efficiently track suicidal presentations to EDs over time, the estimates of prevalence come with varying degrees of error. Therefore, for more detailed and accurate case-level investigations, a manual investigation is still required.

\section{Conclusions}

Data on hospital attendances for all suicide-related concerns (rather than just suicide attempts) provides for a more complete picture of the overall burden suicidality places on public hospital systems. Importantly, such data can inform the development of suicide prevention strategies targeted to those with the highest rates of (re)presentations, such as youth and Indigenous persons.

Findings of the present work offer additional pragmatic opportunities by enabling monitoring of the trends of suicide-related presentations, modelling of future demands, and informing a meaningful distribution of scarce health resources. The importance of timely access to data is particularly evident in times of anticipated changes in suicide risk experienced by broader communities, as seen with the spread of COVID-19 [58]. The fact that over the last 10 years, the increase in suicidal presentations has by far exceeded the increase seen for all ED presentations also highlights the need for consideration of alternative models of care to avoid the overwhelming of health systems [59].

Witt and Robinson [60] note the role machine-learning approaches can play in morbidity surveillance systems by improving timeliness and efficiency while approaching the quality of manualized case ascertainment. The use of the SERoSP algorithm, though not without its limitations, has demonstrated good utility in analyzing a large cohort of suicide-related ED presentations.

Author Contributions: Conceptualization, N.J.C.S., J.S. and K.T.; Formal analysis, N.J.C.S., J.S. and I.H.; Methodology, N.J.C.S., J.S. and I.H.; Software, N.J.C.S.; Writing-original draft, N.J.C.S. and J.S.; Writing-review \& editing, N.J.C.S., J.S., I.H. and K.T. All authors have read and agreed to the published version of the manuscript.

Funding: This research received no external funding.

Conflicts of Interest: The authors declare no conflict of interest. 


\section{References}

1. World Health Organisation (WHO). Preventing Suicide: A Global Imperative; WHO: Geneva, Switzerland, 2014.

2. Australian Bureau of Statistics (ABS). Causes of Death, Australia, 2018; ABS: Canberra, Australia, 2019.

3. Perry, I.J.; Corcoran, P.; Fitzgerald, A.P.; Keeley, H.S.; Reulbach, U.; Arensman, E. The incidence and repetition of hospital-treated deliberate self harm: Findings from the world's first national registry. PLoS ONE 2012, 7, e31663. [CrossRef] [PubMed]

4. Milner, A.; De Leo, D. Who seeks treatment where? Suicidal behaviors and health care: Evidence from a community survey. J. Nerv. Ment. Dis. 2010, 198, 412-419. [CrossRef] [PubMed]

5. De Leo, D.; Cerin, E.; Spathonis, K.; Burgis, S. Lifetime risk of suicide ideation and attempts in an Australian community: Prevalence, suicidal process, and help-seeking behaviour. J. Affect. Disord. 2005, 86, 215-224. [CrossRef] [PubMed]

6. World Health Organisation (WHO). Preventing Suicide A Resource for Non-Fatal Suicidal Behaviour Case Registration; WHO: Geneva, Switzerland, 2014.

7. Geulayov, G.; Casey, D.; Bale, L.; Brand, F.; Clements, C.; Farooq, B.; Kapur, N.; Ness, J.; Waters, K.; Tsiachristas, A.J.T.L.P. Suicide following presentation to hospital for non-fatal self-harm in the Multicentre Study of Self-harm: A long-term follow-up study. Lancet Psychiatry 2019, 6, 1021-1030. [CrossRef]

8. Ceniti, A.K.; Heinecke, N.; McInerney, S.J. Examining suicide-related presentations to the emergency department. Gen. Hosp. Psychiatry 2020, 63, 152-157. [CrossRef]

9. Kõlves, K.; Crompton, D.; Turner, K.; Stapelberg, N.J.; Khan, A.; Robinson, G.; De Leo, D. Trends and repetition of non-fatal suicidal behaviour: Analyses of the Gold Coast University Hospital's Emergency Department. Australas. Psychiatry 2018, 26, 170-175. [CrossRef]

10. Boisseau, C.L.; Yen, S.; Markowitz, J.C.; Grilo, C.M.; Sanislow, C.A.; Shea, M.T.; Zanarini, M.C.; Skodol, A.E.; Gunderson, J.G.; Morey, L.C. Individuals with single versus multiple suicide attempts over 10 years of prospective follow-up. Compr. Psychiatry 2013, 54, 238-242. [CrossRef]

11. Griffin, E.; Bonner, B.; O’Hagan, D.; Kavalidou, K.; Corcoran, P. Hospital-presenting self-harm and ideation: Comparison of incidence, profile and risk of repetition. Gen. Hosp. Psychiatry 2019, 61, 76-81. [CrossRef]

12. Owens, P.L.; Fingar, K.R.; Heslin, K.C.; Mutter, R.; Booth, C.L.J. Emergency Department Visits Related to Suicidal Ideation, 2006-2013: Statistical Brief.\# 220; Agency for Healthcare Research: Rockville, MD, USA, 2017.

13. Cooper, J.; Murphy, E.; Webb, R.; Hawton, K.; Bergen, H.; Waters, K.; Kapur, N. Ethnic differences in self-harm, rates, characteristics and service provision: Three-City cohort study. Br. J. Psychiatry 2010, 197, $212-218$. [CrossRef]

14. Sheehan, A.E.; Walsh, R.F.; Liu, R.T. Racial and ethnic differences in mental health service utilization in suicidal adults: A nationally representative study. J. Psychiatr Res. 2018, 107, 114-119. [CrossRef]

15. Burstein, B.; Agostino, H.; Greenfield, B. Suicidal attempts and ideation among children and adolescents in US emergency departments, 2007-2015. JAMA Pediatr. 2019, 173, 598-600. [CrossRef] [PubMed]

16. Plemmons, G.; Hall, M.; Doupnik, S.; Gay, J.; Brown, C.; Browning, W.; Casey, R.; Freundlich, K.; Johnson, D.P.; Lind, C. Hospitalization for suicide ideation or attempt: 2008-2015. Pediatrics 2018, 141, e20172426. [CrossRef] [PubMed]

17. Perera, J.; Wand, T.; Bein, K.J.; Chalkley, D.; Ivers, R.; Steinbeck, K.S.; Shields, R.; Dinh, M.M. Presentations to NSW emergency departments with self-harm, suicidal ideation, or intentional poisoning, 2010-2014. Med. J. Aust. 2018, 208, 348-353. [CrossRef] [PubMed]

18. Sveticic, J.; Stapelberg, N.C.; Turner, K. Suicidal and self-harm presentations to emergency departments: The challenges of identification through diagnostic codes and presenting complaints. Health Inf. Manag. J. 2020, 49, 38. [CrossRef]

19. Randall, J.R.; Roos, L.L.; Lix, L.M.; Katz, L.Y.; Bolton, J.M. Emergency department and inpatient coding for self-harm and suicide attempts: Validation using clinician assessment data. Int. J. Methods Psychiatr. Res. 2017, 26, e1559. [CrossRef]

20. Walkup, J.T.; Townsend, L.; Crystal, S.; Olfson, M. A systematic review of validated methods for identifying suicide or suicidal ideation using administrative or claims data. Pharmacoepidemiol. Drug Saf. 2012, 21, 174-182. [CrossRef]

21. Gold Coast Health. Gold Coast Mental Health Suicide Prevention Strategy 2016-2018; Gold Coast Hospital and Health Services: Southport, Queensland, Australia, 2016. 
22. Covington, D.; Hogan, M.; Abreu, J.; Berman, A.; Breux, P.; Coffey, E.; Comeau, C.; Comtois, K.; Damle, C.; Davidson, L. Suicide Care in Systems Framework, National Action Alliance, Clinical Care \& Intervention Task Force. Available online: https://theactionalliance.org/resource/suicide-care-systems-framework (accessed on 10 July 2020).

23. Stapelberg, N.C.; Randall, M.; Fugelli, P.; Sveticic, J.; Dave, H.; Turner, K. Data Mining for Records of Suicidal and Self-Harm Presentations to Hospital and Health Service Emergency Departments Using an Evolutionary Algorithm. Expert Syst. Appl. 2020. (under review).

24. Australian Bureau of Statistics. ABS.Stat. Available online: http://stat.data.abs.gov.au/ (accessed on 1 July 2020).

25. Lalkhen, A.G.; McCluskey, A. Clinical tests: Sensitivity and specificity. Anaesth. Crit. Care Pain 2008, 8, 221-223. [CrossRef]

26. Maxim, L.D.; Niebo, R.; Utell, M.J. Screening tests: A review with examples. Inhal. Toxicol. 2014, 26, 811-828. [CrossRef]

27. Messam, L.L.M.; Branscum, A.J.; Collins, M.T.; Gardner, I.A. Frequentist and Bayesian approaches to prevalence estimation using examples from Johne's disease. Anim. Health Res. Rev. 2008, 9, 1-23. [CrossRef]

28. Lang, Z.; Reiczigel, J. Confidence limits for prevalence of disease adjusted for estimated sensitivity and specificity. Prev. Vet. Med. 2014, 113, 13-22. [CrossRef] [PubMed]

29. Sanogo, M.; Abatih, E.; Saegerman, C. Bayesian versus frequentist methods for estimating disease true prevalence and 4 diagnostic test performance. Vet. J. 2014, 202, 204-207. [CrossRef] [PubMed]

30. Joseph, L.; Gyorkos, T.W.; Coupal, L. Bayesian estimation of disease prevalence and the parameters of diagnostic tests in the absence of a gold standard. Am. J. Epidemiol. 1995, 141, 263-272. [CrossRef] [PubMed]

31. Sergeant, E. Epitools Epidemiological Calculators. Available online: http://epitools.ausvet.com (accessed on 1 July 2020).

32. IBM. SPSS Statistics for Windows, Version 24; IBM: Armonk, NY, US, 2016.

33. Haw, C.; Bergen, H.; Casey, D.; Hawton, K. Repetition of deliberate self-harm: A study of the characteristics and subsequent deaths in patients presenting to a general hospital according to extent of repetition. Suicide Life Threat. Behav. 2007, 37, 379-396. [CrossRef]

34. Ting, S.A.; Sullivan, A.F.; Boudreaux, E.D.; Miller, I.; Camargo, C.A., Jr. Trends in US emergency department visits for attempted suicide and self-inflicted injury, 1993-2008. Gen. Hosp. Psychiatry 2012, 34, 557-565. [CrossRef]

35. Milner, A.; Niven, H.; LaMontagne, A.D. Occupational class differences in suicide: Evidence of changes over time and during the global financial crisis in Australia. BMC Psychiatry 2015, 15, 223-230. [CrossRef]

36. Bruffaerts, R.; Demyttenaere, K.; Hwang, I.; Chiu, W.-T.; Sampson, N.; Kessler, R.C.; Alonso, J.; Borges, G.; de Girolamo, G.; de Graaf, R. Treatment of suicidal people around the world. Br. J. Psychiatry 2011, 199, 64-70. [CrossRef]

37. Hom, M.A.; Stanley, I.H.; Joiner, T.E., Jr. Evaluating factors and interventions that influence help-seeking and mental health service utilization among suicidal individuals: A review of the literature. Clin. Psychol. Rev. 2015, 40, 28-39. [CrossRef]

38. Stanley, B.; Brown, G.K.; Currier, G.W.; Lyons, C.; Chesin, M.; Knox, K.L. Brief intervention and follow-up for suicidal patients with repeat emergency department visits enhances treatment engagement. Am. J. Public Health 2015, 105, 1570-1572. [CrossRef]

39. Queensland Health. Suicide Prevention in Health Services Initiative, Year 1 Progress Report 2016-2017; Queensland Health: Brisbane, Australia, 2018.

40. Qin, P.; Agerbo, E.; Mortensen, P.B. Suicide risk in relation to socioeconomic, demographic, psychiatric, and familial factors: A national register-based study of all suicides in Denmark, 1981-1997. Am. J. Psychiatry 2003, 160, 765-772. [CrossRef]

41. Mergl, R.; Havers, I.; Althaus, D.; Rihmer, Z.; Schmidtke, A.; Lehfeld, H.; Niklewski, G.; Hegerl, U. Seasonality of suicide attempts: Association with gender. Eur. Arch. Psychiatry Clin. Neurosci. 2010, 260, 393-400. [CrossRef] [PubMed]

42. Sedgwick, R.; Epstein, S.; Dutta, R.; Ougrin, D. Social media, internet use and suicide attempts in adolescents. Curr. Opin. Psychiatry 2019, 32, 534-541. [CrossRef] [PubMed]

43. Larkin, G.L.; Smith, R.P.; Beautrais, A.L. Trends in US emergency department visits for suicide attempts, 1992-2001. Crisis 2008, 29, 73-80. [CrossRef] [PubMed] 
44. Kolves, K.; De Leo, D. Are immigrants responsible for the recent decline in Australian suicide rates? Epidemiol. Psychiatr Sci. 2015, 24, 241-248. [CrossRef] [PubMed]

45. Selkirk, M.; Quayle, E.; Rothwell, N. A systematic review of factors affecting migrant attitudes towards seeking psychological help. J. Health Care Poor Underserved 2014, 25, 94-127. [CrossRef] [PubMed]

46. Farrelly, T. The Aboriginal suicide and self-harm help-seeking quandary. AIHWJ 2008, 32, 11.

47. De Leo, D.; Sveticic, J.; Milner, A. Suicide in Indigenous people in Queensland, Australia: Trends and methods, 1994-2007. Aust. N. Z. J. Psychiatry 2011, 45, 532-538. [CrossRef]

48. Vicary, D.; Westerman, T. That's just the way he is': Some implications of Aboriginal mental health beliefs. AeJAMH 2004, 3, 103-112. [CrossRef]

49. Nagel, T. Involuntary mental health treatment in the remote Northern Territory. Psychiatry Psychol. Law 2003, 10, 171-178. [CrossRef]

50. Cantor, C.; Hickey, P.; De Leo, D. Seasonal variation in suicide in a predominantly Caucasian tropical/subtropical region of Australia. Psychopath 2000, 33, 303-306. [CrossRef]

51. Law, C.-K.; De Leo, D. Seasonal differences in the day-of-the-week pattern of suicide in Queensland, Australia. Int. J. Environ. Res. Public Health 2013, 10, 2825-2833. [CrossRef] [PubMed]

52. Yang, A.C.; Huang, N.E.; Peng, C.-K.; Tsai, S.-J. Do seasons have an influence on the incidence of depression? The use of an internet search engine query data as a proxy of human affect. PLOS ONE 2010, 5, e13728. [CrossRef] [PubMed]

53. Boyle, J.; Jessup, M.; Crilly, J.; Green, D.; Lind, J.; Wallis, M.; Miller, P.; Fitzgerald, G. Predicting emergency department admissions. Emerg. Med. J. 2012, 29, 358-365. [CrossRef] [PubMed]

54. Crilly, J.; Ranse, J.; Bost, N.; Donnelly, T.; Timms, J.; Gilmour, K.; Aitken, M.; Johnston, A. Emergency healthcare delivery for young adults during a planned mass gathering: A retrospective observational study. Emerg. Med. Australas 2020, 32, 250-257. [CrossRef] [PubMed]

55. O'Loughlin, M.; Harriss, L.; Mills, J.; Thompson, F.; McDermott, R. Validating Indigenous status in a regional Queensland hospital emergency department dataset with patient-linked data. Med. J. Aust. 2020, 212, 230-231. [CrossRef]

56. Tran, D.T.; Jorm, L.; Lujic, S.; Bambrick, H.; Johnson, M. Country of birth recording in Australian hospital morbidity data: Accuracy and predictors. Aust. N. Z. J. Public Health 2012, 36, 310-316. [CrossRef]

57. Queensland Health. Aboriginal and Torres Strait Islander Mental Health Strategy 2016-2021; Aboriginal and Torres Strait Islander Health Branch, Department of Health: Brisbane, Australia, 2016.

58. Gunnell, D.; Appleby, L.; Arensman, E.; Hawton, K.; John, A.; Kapur, N.; Khan, M. Suicide risk and prevention during the COVID-19 pandemic. Lancet Psychiatry 2020, 7, 468-471. [CrossRef]

59. Saxon, V.; Mukherjee, D.; Thomas, D. Behavioral Health Crisis Stabilization Centers: A New Normal. J. Ment. Health Clin. Psychol. 2018, 2, 23-26. [CrossRef]

60. Witt, K.; Robinson, J. Sentinel surveillance for self-harm. Crisis 2019, 40, 1-6. [CrossRef]

(C) 2020 by the authors. Licensee MDPI, Basel, Switzerland. This article is an open access article distributed under the terms and conditions of the Creative Commons Attribution (CC BY) license (http://creativecommons.org/licenses/by/4.0/). 